\title{
0 racismo institucional sob a perspectiva da ética do cuidado, nos serviços de saúde: revisão integrativa
}

\author{
Institutional racism from the perspective of care ethics in health services: an integrative review \\ Racismo institucional desde la perspectiva de la ética del cuidado en los servicios de salud: una revisión integradora
}

\begin{abstract}
RESUMO
Objetivou-se analisar, em literatura nacional e internacional, o racismo institucional nos serviços de saúde sob o olhar da ética considerando que problemas éticos são desafios que contam com vários cursos de ação para sua solução ou manejo, exigindo deliberação e ponderação a fim de encontrar o melhor caminho, o qual por sua vez, necessita ser continuamente reavaliado. Optou-se como método a revisão integrativa a partir da questão norteadora: Quais as evidências científicas sobre o racismo institucional nos serviços de saúde? A busca foi realizada na Biblioteca Virtual em Saúde e na base Scopus. A partir do levantamento realizado, o corpus do estudo foi constituído por 15 estudos. A análise resultou em três categorias temáticas: Abordagem da definição de Racismo Institucional, Barreiras no acesso a serviços de saúde e Disparidades nos índices de morbimortalidade. A ética no cuidado vem para fundamentar nossas funções e responsabilidades diante dos clientes. Ao refletirmos sobre a forma como estamos realizando os cuidados e as consequências de nossos atos sobre os pacientes, passamos a dar valor a todos os nossos atos, desde os menores atos até as grandes ações.
\end{abstract}

DESCRITORES: Ética; Racismo; Serviços de Saúde.

\section{ABSTRACT}

The aim of this study was to analyze, in national and international literature, institutional racism in health services from the perspective of ethics considering that ethical problems are challenges that have several courses of action for their solution or management, requiring deliberation and consideration in order to find the best path, which in turn, needs to be continually reassessed. The integrative review was chosen as the method based on the guiding question: What is the scientific evidence on institutional racism in health services? The search was carried out at the Virtual Health Library and at the Scopus base. From the survey carried out, the study corpus consisted of 15 studies. The analysis resulted in three thematic categories: Approach to the definition of Institutional Racism, Barriers to accessing health services and Disparities in morbidity and mortality rates. Ethics in care comes to support our functions and responsibilities towards clients. When we reflect on the way we are carrying out the care and the consequences of our actions on patients, we start to value all our actions, from the smallest acts to the great actions.

DESCRIPTORS: Ethics; Racism; Health Services.

\section{RESUMEN}

El objetivo de este estudio fue analizar, en la literatura nacional e internacional, el racismo institucional en los servicios de salud desde la perspectiva de la ética considerando que los problemas éticos son desafíos que tienen varios cursos de acción para su solución o manejo, requiriendo deliberación y consideración para encontrar el mejor camino, que a su vez, debe reevaluarse continuamente. Se eligió la revisión integradora como método basado en la pregunta orientadora: ¿Cuál es la evidencia científica sobre el racismo institucional en los servicios de salud? La búsqueda se realizó en la Biblioteca Virtual en Salud y en la base Scopus. De la encuesta realizada, el corpus de estudio estuvo conformado por 15 estudios. El análisis resultó en tres categorías temáticas: Aproximación a la definición de Racismo Institucional, Barreras para acceder a los servicios de salud y Disparidades en las tasas de morbilidad y mortalidad. La ética en el cuidado viene a respaldar nuestras funciones y responsabilidades hacia los clientes. Cuando reflexionamos sobre la forma en que estamos Ilevando a cabo los cuidados y las consecuencias de nuestras acciones en los pacientes, comenzamos a valorar todas nuestras acciones, desde los actos más pequeños hasta las grandes acciones.

DESCRIPTORES: Ética; Racismo; Servicios de Salud.

RECEBIDO EM: 16/03/2020 APROVADO EM: 16/03/2020 


\section{Roberta Georgia Sousa dos Santos}

Mestre em Enfermagem. Doutoranda do Programa de Pós Graduação de Bioética, Ética Aplicada e Saúde Coletiva - PPGBIOS. ORCID: 0000-0002-2122-2505

\section{Marisa Palacios da Cunha e Melo de Almeida Rego}

Doutora em Engenharia de Produção. Professora Titular de Bioética da Universidade Federal do Rio de Janeiro. Diretora do Núcleo de Bioética e Ética Aplicada da UFRJ.

ORCID: 0000-0001-6507-4199

\section{INTRODUÇÃO}

D iante da diversidade de cor/raça e culturas em diferentes países, se faz necessário o reconhecimento de necessidades de saúde de indivíduos e familiares dos diferentes grupos da população de um determinado território que, por sua vez, devem ser tomadas como objeto das práticas de saúde, para que essas sejam operacionalizadas em resposta às necessidades que as originaram, numa circularidade entre necessidades de saúde e trabalho em saúde. As necessidades de saúde não se restringem a necessidades médicas, de serviços de saúde, nem a problemas de saúde, mas dizem respeito à carência ou vulnerabilidades que expressam modos de vida e identidades.

Para uma análise adequada das condições sociais e da saúde da população, é preciso ainda considerar a grave e insistente questão do racismo, persistente mesmo após uma série de conquistas institucionais, devido ao seu elevado grau de estranhamento na cultura brasileira. $\mathrm{O}$ racismo se reafirma no dia a dia pela linguagem comum, se mantém e se alimenta pela tradição e pela cultura, influencia a vida, o funcionamento das instituições, das organizações e também as relações entre as pessoas; é condição histórica e traz consigo o preconceito e a discriminação, afetando a população negra de todas as camadas sociais ${ }^{(1)}$.

Do ponto de vista institucional - que envolve as políticas, os programas e as relações interpessoais -, deve se considerar que as instituições comprometem sua atuação quando deixam de oferecer um serviço qualificado às pessoas em função da sua origem étnico-racial, cor da pele ou cultura. Esse comprometimento é resultante do racismo institucional.
O racismo institucional constitui-se na produção sistemática da segregação étnico-racial nos processos institucionais. Manifesta-se por meio de normas, práticas e comportamentos discriminatórios adotados no cotidiano de trabalho, resultantes da ignorância, falta de atenção, preconceitos ou estereótipos racistas. Em qualquer caso, sempre coloca pessoas de grupos raciais ou étnicos discriminados em situação de desvantagem no acesso a benefícios gerados pela ação das instituições e organizações ${ }^{(1)}$.

Pensando em organizar o combate ao racismo institucional, cria-se duas dimensões, a primeira é a da relação interpessoal, a segunda é a político programática, sendo as duas tratadas de maneira interdependente. A dimensão relação interpessoal é caracterizada pelas relações que se estabelecem entre dirigentes e servidores, entre os próprios servidores e entre os servidores e os usuários dos serviços.

Já a dimensão político programática é caracterizada pela produção e disseminação de informações sobre as experiências diferentes e/ou desiguais em nascer, viver, adoecer e morrer; pela capacidade em reconhecer o racismo como um dos determinantes das desigualdades no processo de ampliação das potencialidades individuais; pelo investimento em ações e programas específicos para a identificação de práticas discriminatórias; pelas possibilidades de elaboração e implementação de mecanismos e estratégias de não-discriminação, combate e prevenção do racismo e intolerâncias correlatas - incluindo a sensibilização e capacitação de profissionais; pelo compromisso em priorizar a formulação e implementação de mecanismos e estratégias de redução das disparidades e promoção da equidade ${ }^{(1)}$.

$\mathrm{O}$ objetivo deste estudo foi analisar, em literatura nacional e internacional, o racismo institucional nos serviços de saúde sob o olhar da ética, considerando que problemas éticos são desafios que contam com vários cursos de ação para sua solução ou manejo, exigindo deliberação e ponderação a fim de encontrar o melhor caminho, o qual, por sua vez, necessita ser continuamente reavaliado. Problemas éticos não podem ser resolvidos com receitas prontas, mas exigem permanente criatividade, de modo a abrir novas alternativas de soluções, tendo em vista a excelência ética na prática dos serviços de atenção à saúde ${ }^{(2)}$.

A ética na saúde tentou equilibrar os princípios, como beneficência, autonomia e justiça para abordar dilemas; como tal, disparidades em saúde têm sido vistas como um fator de justiça social. A transformação de cuidados de saúde propõe reformular esta lente, acrescentando que para abordar as disparidades não só é preciso falar de justiça social, como também das questões éticas. O cuidado centrado no paciente/ usuário requer conhecimento de competência cultural e a ética do cuidar.

\section{METODOLOGIA}

Optou-se como método a revisão integrativa, método específico, que resume o passado da literatura empírica ou teórica, para fornecer uma compreensão mais abrangente de um fenômeno particular $^{(3)}$. A revisão integrativa possibilita a síntese de estudos já publicados, permitindo a geração de novos conhecimentos embasada em resultados apresentados por pesquisas. Esta metodologia também contribui para determinar o conhecimento atual sobre uma temática específica, já que é conduzida de modo a identificar, 
analisar e sintetizar resultados de estudos independentes sobre o mesmo assunto, con $\neg$ tribuindo, pois, para uma possível repercussão benéfi-ca na qualidade dos cuidados prestados ao paciente ${ }^{(4)}$.

Seis etapas foram realizadas para o desenvolvimento da revisão: a primeira etapa foi a definição da questão norteadora da pesquisa, na segunda etapa foram delimitados os critérios de inclusão e exclusão, na terceira etapa foram eleitas as bases de dados e realizada a busca das produções científicas, na quarta etapa foi realizada a análise dos dados, na quinta etapa foi desenvolvida a discussão dos dados e na sexta etapa foi apresentada a síntese da revisão ${ }^{(4)}$.

A questão norteadora do estudo foi: "Quais as evidências científicas sobre o racismo institucional nos serviços de saúde?". Para responder a este questionamento, realizou-se uma pesquisa on-line nas bases de dados: disponíveis na Biblioteca
Virtual de Saúde (BVS) e na base Scopus. Os critérios de inclusão empregados foram: artigos disponíveis na íntegra, on-line de maneira gratuita, produções nacionais e internacionais, tendo serviços de saúde como cenário de estudo. Os critérios de exclusão: teses, dissertações, monografias, repetição nas bases de dados e artigos que após a leitura não convergirem com o objeto de estudo. O espaço temporal não foi delimitado a fim de identificar o maior número possível de estudos produzidos com esta temática.

A busca de dados do estudo foi realizada entre setembro e novembro de 2019. Este estudo é parte da construção de um projeto de pesquisa de doutorado e teve participação da doutoranda, o orientador e coorientadora. Os descritores utilizados foram: "Ethics AND Racism AND Health Services".

Após a leitura de 29 artigos na íntegra, 14 foram excluídos por diferentes moti-
Figura 1. Esquema representativo do processo da busca de artigos. Rio de Janeiro, RJ, Brasil, 2019

Publicação identificadas na Biblioteca Virtual da Saúde e Scopus Descritores: " ethics" and "racism" and " health services"

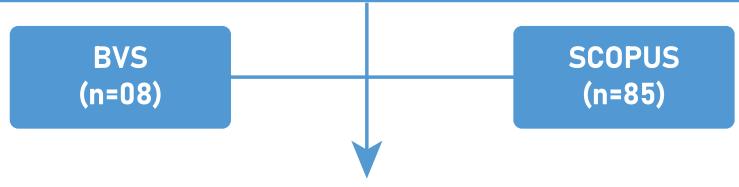

Critérios de Inclusão e Exclusão ( $n=58)$ Exclusão dos artigos repetifdos ( $n=14)$

Publicação analisadas na íntrifra $(n=44)$

Eclusão dos artigos que não atendiam o objetivo do estudo $(n=29)$

Artigos selecionados para revisão integrativa $(n=15)$

Artigos BVS $(n=03)$

Artigos ScopUs $(n=12)$ vos, cujos quais apenas citavam a questão do racismo institucional no sistema de saúde e tinham como foco central a discussão em áreas como a educação e segurança pública. $\mathrm{O}$ estudo constitui-se dos 15 artigos selecionados, que foram integrados à revisão.

Por meio de análise temática ou categorial tipo de técnica de análise de conteúdo(5), operou-se de desmembramento do texto em unidades (categorias), segundo reagrupamentos sistemáticos analógicos. A análise de conteúdo de mensagens deveria ser aplicável a todas as formas de comunicação, pois possui duas funções que podem ou não se dissociar quando colocadas em práticas. A primeira diz que, a análise de conteúdo enriquece a tentativa exploratória e aumenta a propensão à descoberta. A segunda se refere à administração da prova, em que hipóteses, sob a forma de questões ou de afirmações provisórias servem de diretrizes apelando para o método de análise de uma confirmação ou de uma informação ${ }^{(5)}$.

$\operatorname{Bardin}^{(5)}$ sinaliza três etapas para a análise de conteúdo. A pré-análise, é a primeira, que consiste na organização de todos os materiais que serão utilizados para a coleta dos dados, assim como também como outros materiais que podem ajudar a entender melhor o fenômeno e fixar o que o autor define como corpus da investigação, que seria a especificação do campo que o pesquisador deve centrar a atenção.

A descrição analítica é a segunda etapa, onde o material reunido que constitui o corpus da pesquisa é mais bem aprofundado, sendo orientado em princípio pelas hipóteses e pelo referencial teórico, surgindo desta análise quadros de referências, buscando sínteses coincidentes e divergentes de ideias. A terceira etapa, e não menos importante, é a interpretação referencial, fase de análise propriamente dita.

A análise de conteúdo não obedece à etapa rígida, mas sim a uma reconstrução simultânea com as percepções do pesquisador com vias possíveis nem sempre claramente balizadas. 


\section{artigo}

\section{RESULTADOS E DISCUSSÃO}

A partir do levantamento realizado e descrito anteriormente, o corpus do estudo, será constituído por 15 estudos, que estão apresentados no Quadro 1 abaixo.

$\mathrm{Na}$ análise dos 15 artigos selecionados para revisão, alguns pontos foram destacados. Um destes pontos é que apenas um artigo foi construído no Brasil, no ano de 2007, o que demonstra que a temática do racismo institucional relacionada a questões éticas nos serviços de saúde ainda não vem sendo discutida de maneira ampla entre os pesquisadores brasileiros.

De acordo com as publicações por ano, os estudos ficaram distribuídos da seguinte forma: 2002 (1), 2006 (1), 2007 (4), 2008 (2), 2009 (2), 2012 (1), 2013 (1), 2014 (2) e 2015 (1), mais de
$50 \%$ deles foram publicados nos últimos dez anos.

\section{Abordagem da definição de Racismo Institucional}

"É o racismo que existe de forma sistêmica $e$ institucional, onde a produção, controle e acesso a recursos atua em benefício de grupos raciais / culturais selecionados e prejudica outros ${ }^{(6)}$."

"O racismo institucional é definido como o "fracasso coletivo de uma organização para prover um serviço apropriado e profissional para as pessoas por causa de sua cor, cultura ou origem étnica. Ele pode ser visto ou detectado em processos, atitudes e comportamentos que totalizam em discriminação por preconceito involuntário, ignorância, negligência e estereotipação racista, que causa desvantagens a pessoas de minoria étnica ${ }^{(7)}$."

Dos 15 artigos selecionados, apenas três abordaram a definição de racismo institucional. Um artigo australiano produzido em 2012 e dois artigos publicados no ano de 2007, um no Brasil e o outro na Inglaterra.

Na década de 1960, a luta pelos direitos civis nos Estados Unidos, a luta contra o apartheid na África do Sul e o fim do colonialismo nos países africanos e asiáticos representaram mudanças profundas nos estudos sobre o racismo no mundo. Reconheceu-se que as instituições, práticas administrativas e estruturas políticas e so-

Quadro 1. Artigos selecionados de acordo com a cronologia das publicações, título, periódico, método e país de origem da pesquisa. Rio de Janeiro, RJ, Brasil, 2019

\begin{tabular}{|c|c|c|c|c|}
\hline ANO & TÍTULO & PERIÓDICO & MÉTODO & PÁIS \\
\hline 2002 & Race and Healthcare Disparities: Overcoming Vulnerability & Theoretical Medicine & Revisão & EUA \\
\hline 2006 & Disparities in Pain: Ethical Issues & Ethics Forum & Revisão & EUA \\
\hline 2007 & Racismo Institucional: um desafio para a equidade no SUS? & Saúde e Sociedade & Estudo exploratório & Brasil \\
\hline 2007 & Institutional racism in mental health care & BMJ & Estudo de Reflexão & Inglaterra \\
\hline 2007 & American Indian Women, HIV/AIDS, and Health Disparity & Informa Health Care & Estudo de Reflexão & EUA \\
\hline 2007 & $\begin{array}{l}\text { Telling Stories: nurses, politics and aboriginal Australians, circa } \\
1900 \text { and 1980s. }\end{array}$ & Contemporane Nurse & Pesquisa Documental & Austrália \\
\hline 2008 & The Neglect of Racism as an Ethical Issue in Health Care & $\begin{array}{l}J \text { Immigrant Minority } \\
\text { Health }\end{array}$ & Revisão & Austrália \\
\hline 2008 & $\begin{array}{l}\text { Disparity vs Inequity: Toward Reconceptualization of Pain Tre- } \\
\text { atment Disparities }\end{array}$ & Pain Medicine & Revisão & EUA \\
\hline 2009 & $\begin{array}{l}\text { Racism and inequalities in health: notes towards an agenda for } \\
\text { critical health psychology }\end{array}$ & $\begin{array}{l}\text { Journal of Health } \\
\text { Psychology }\end{array}$ & Estudo de Reflexão & Nova Zelândia \\
\hline 2009 & $\begin{array}{l}\text { Harms and benefits: Collecting ethnicity data in a clinical } \\
\text { context }\end{array}$ & $\begin{array}{l}\text { Social Science \& Me- } \\
\text { dicine }\end{array}$ & Pesquisa Etnográfica & Canadá \\
\hline 2012 & $\begin{array}{l}\text { Reducing the health disparities of Indigenous Australians: time } \\
\text { to change focus }\end{array}$ & $\begin{array}{l}\text { BMC Health Services } \\
\text { Research }\end{array}$ & Pesquisa de campo & Austrália \\
\hline 2013 & $\begin{array}{l}\text { Public health genomics: a new space for a dialogue on racism } \\
\text { through Community Based Participatory Research }\end{array}$ & Public Health & Editorial & EUA \\
\hline 2014 & $\begin{array}{l}\text { Understanding Inequalities in Access to Health Care Services } \\
\text { for Aboriginal People A Call for Nursing Action }\end{array}$ & $\begin{array}{l}\text { Advances in Nursing } \\
\text { Science }\end{array}$ & Pesquisa de campo & Canadá \\
\hline 2014 & $\begin{array}{l}\text { Addressing Disparities and Achieving Equity Cultural Compe- } \\
\text { tence, Ethics, and Health-care Transformation }\end{array}$ & CHEST & Pesquisa de campo & EUA \\
\hline 2015 & $\begin{array}{l}\text { Unconscious Race and Social Class Bias Among Acute Care } \\
\text { Surgical Clinicians and Clinical Treatment Decisions. }\end{array}$ & JAMA Surg. & Estudo de Reflexão & EUA \\
\hline
\end{tabular}


ciais podiam agir de maneira adversa e racialmente discriminatória ou excludente. O conceito de racismo foi ampliado para cobrir as formas de racismo institucional e racismo estrutural. $\mathrm{O}$ racismo passou a ser identificado como uma situação que poderia ocorrer independentemente $\mathrm{da}$ vontade das pessoas, reconhecendo que certas práticas, realizadas por instituições, não têm atitudes, mas podem certamente discriminar, criar obstáculos, impedir e prejudicar os interesses de um grupo por causa de sua raça, de sua $\operatorname{cor}^{(9)}$.

Stokely Carmichael e Charles V. Hamilton, dois militantes do movimento negro norte-americado, apresentam a distinção entre racismo individual e estrutural (institucional) no livro "Black Power: the politics of liberation”, 1967. Para os autores, o racismo individual apresenta-se de uma forma aberta e associada aos indivíduos, e o estrutural (institucional) de outra forma, não declarada e institucional, "trata-se da falha coletiva de uma organização em prover um serviço apropriado e profissional às pessoas por causa de sua cor, cultura ou origem étnica”. O importante dessa análise é que passa a dissociar o racismo de atos e intenções ou da consciência de alguns atores ${ }^{(9)}$.

O racismo é constituído de um dispositivo crucial do poder exercido historicamente para desagregar e sujeitar povos, classes, etnias e raças. Os negros sofrem não só essa segregação racial propícia ao preconceito racial e operada no plano privado, mas sobretudo o racismo institucional, que transmite e se materializa nas políticas estatais que lhes são dirigidas. Trata-se de distinção racial exercida pelos Estados ao exercer de forma diferenciada em relação a esses segmentos populacionais, cruzando em nossas cidades e sociedade, pelo rumo das políticas públicas, uma abertura entre o que deve se manter vivo e o que deve perecer. Dentre as formas de racismo existe o racismo institucional ${ }^{(10)}$.

De encontro a essas considerações, em 2013, Werneck ${ }^{(11)}$ definiu o racismo institucional como "um modo de subordinar o direito e a democracia às necessidades do racismo, fazendo com que os primei-
A prática do racismo institucional na área da saúde afeta preponderantemente as populações negra e indígena. A invisibilidade das

doenças que são mais prevalentes

\section{nestes grupos}

populacionais, a não

inclusão da questão

racial nos aparelhos

de formação, a

dificuldade de acesso

aos serviços de

saúde... ros inexistam ou existam de forma precária, diante de barreiras interpostas na vivência dos grupos e indivíduos aprisionados pelos esquemas de subordinação desse último".

Nas organizações de saúde, o racismo institucional é percebido nas políticas que desconsideram os diferentes tipos de doenças e mortes entre brancos e negros; no desenvolvimento dos profissionais onde não é incluso o debate sobre temas raciais; pela indiferença na atenção e tratamento, entre outras maneiras tênues como mudez e olhares. O envolvimento dos profissionais no combate ao racismo nas instituições de saúde é de grande importância e vem embasado nos princípios éticos ${ }^{(7)}$.

A prática do racismo institucional na área da saúde afeta preponderantemente as populações negra e indígena. A invisibilidade das doenças que são mais prevalentes nestes grupos populacionais, a não inclusão da questão racial nos aparelhos de formação, a dificuldade de acesso aos serviços de saúde, a qualidade da atenção à saúde, assim como o acesso aos insumos, determina diferenças importantes nos perfis de adoecimento e morte entre brancos e negros ${ }^{(6)}$.

Ética de cuidados de saúde, por sua própria natureza, envolve valores, visualizações e proposições que convidam e provocar controvérsia. As questões éticas como o aborto, a eutanásia, a tomada de decisões de fim de vida, tecnologia de reprodução, engenharia genética, para citar alguns, são todos familiarizados temas de debate e discordância do profissional de saúde nas literaturas. Um tópico menos familiar na ética de cuidados de saúde, no entanto, é o de racismo. Apenas porque o racismo como tema da ética do cuidado foi esquecido.

\section{Barreiras no acesso a serviços de saúde \\ Kalckman $^{(7)}$, em Racismo Institucio- nal: um desafio para a equidade no SUS? Destacam que o racismo institucional no Brasil, atinge principalmente a popula- ção de negros e índios. O estudo eviden-}


ciou que em momentos de fragilidade como no parto e pré-natal, as situaçóes de discriminação ficam mais frequentes.

"[...] a dificuldade de acesso aos serviços de saúde, a qualidade da atenção à saúde, de tal modo como o acesso aos insumos, determina diferenças importantes nos perfis de adoecimento e morte entre brancos e negros" (7).

Thompson e Durey ${ }^{(6)}$ abordam as disparidades em saúde vivenciadas pela população aborígene, discutem como o racismo proporciona a este grupo da população, experiências coletivas, memória de abuso, insensibilidade e estão mais propensos a sofrerem discriminação nos serviços de saúde.

Segundo Cameron ${ }^{(12)}$, histórias de racismo, estigmatização, assédio e medo foram descritos pelos participantes de sua pesquisa como fatores considerados como barreiras no acesso aos serviços de saúde. Os participantes também descreveram que necessidades de atenção médica como exames laboratoriais e consultas com especialistas não eram uns problemas/barreira e sim a interação com os profissionais de saúde e o vocabulário técnico utilizado muitas das vezes.

Estudo $^{(12)}$ relatou experiências de acesso a um serviço de emergência, por aborígenes e não-aborígenes. $\mathrm{O}$ que se destacou deste trabalho foi a significância de experiências de cuidados de saúde pessoais, sociais vividos anteriormente que influenciam no acesso do povo indígena aos serviços de emergência. Relatos claros de participantes do estudo mostra que o acesso a cuidados vai incluir primeiramente superar inibições contrarias a procura. Relata ainda que os participantes afirmam de forma clara que o acesso a cuidados inclui primeiramente em superação de inibições contra a busca de cuidado devido às experiências negativas vividas no passado que influenciaram no acesso aos cuidados. Isso torna relevante na hora de entender a disparidade e a desigualdade no acesso aos cuidados de saúde que muitos indivíduos aborígenes vivenciaram no Canadá.

Segundo Kalckman ${ }^{(7)}$, o relato de uma enfermeira de 32 anos de cor preta, associa a cor da pele ao baixo poder aquisitivo, parecendo está cada vez mais comum e constante:

"A recepcionista demorou para me dar atenção e quando eu entreguei o cartão do convênio, ela olhou duas vezes para mim, pediu o meu $R G$, coisa que não havia feito com outras pacientes brancas, ela parecia não acreditar que eu pudesse pagar o convênio. Nos tratam como um ser de segunda categoria, até mesmo a solicitação do documento de identidade, pode ser interpretado como 'tirar a prova real' será que essa pessoa realmente é beneficiária deste plano?".

Os participantes descreveram que, como as experiências anteriores com serviços de saúde haviam sido negativas, não houve encorajamento para o desenvolvimento de uma relação de confiança com os profissionais. $\mathrm{O}$ acesso continua a ser insuficiente, porque para a ligação entre o controle local de serviços e práticas de saúde não é dada a devida atenção ${ }^{(12)}$.

A população, muitas das vezes, visualiza o racismo institucional nos serviços de saúde como uma postura interpessoal, no entanto, sua apresentação nestes casos é de forma sistêmica e institucional, pois existe a produção do controle e acesso aos recursos, colocando determinados grupos raciais em vantagem. Essa estrutura de privilégios aumenta as iniquidades no que tange ao acesso ferindo o direito desta população à informação adequada e um tratamento equitativo.

A igualdade de acesso aos serviços de saúde é de significativa importância para a redução das desigualdades e barreiras de acesso aos serviços de saúde. Contudo, os indivíduos aborígenes, indígenas e negros vivenciam essa experiência com relatos de dificuldade e/ou acesso limitados a estes serviços.

$\mathrm{O}$ acesso, segundo resguarda a Lei de Saúde, tem por definição a distribuição equitativa de serviços aos desfavorecidos para o bem comum e saúde para toda população, esse acesso à saúde não está ligado meramente ao serviço prestado a esse indivíduo de forma geral, mas tambem a forma como esse serviço chega ao local de atendimento. Tendo em vista que esse acesso é um divisor de águas no que tange ao determinante social da saúde ${ }^{(12)}$.

Contudo, nem todos os canadenses fazem uso dessa igualdade de acesso aos serviços de saúde. Existe uma persistente desigualdade no estado e acesso aos serviços de saúde para a população aborígene, configurando em uma preocupação na forma como eles enfrentam as barreiras para atingir o ingresso equitativo ${ }^{(12)}$.

Essa tem sido uma longa caminhada, contudo, fica evidenciada a relevância gerada quanto aos comprometidos deste trabalho com muitos parceiros, no intuito de despertar um sistema de saúde mais humanizado e mais sensível, para esta população menos favorecida que suporta a desigualdade, tornando um apelo ético e político desse povo aborígene a tomada de decisão quanto à esta lacuna ${ }^{(12)}$.

\section{Disparidades nos índices de morbi- mortalidade}

Há tempos que estudos vem demonstrando que existe um perfil nas desigualdades raciais no acesso a serviços de saúde que tem como consequência grave uma disparidade nos dados de morbimortalidade de algumas situações como, as doenças prevalentes na população não serem tratadas como um problema de saúde pública ou dos índices altos de mortalidade materna e infantil deste grupo.

Stephens e Christine ${ }^{(13)}$ relatam que existe um grupo de indígenas com estado de saúde muito precário na Austrália. A estimativa de vida da população indígena é 17 anos menor do que os brancos australianos; a letalidade infantil é de 3 vezes maior; as taxas de mortalidade para os indígenas australianos, diante de todos os grupos etários, são duas vezes mais altas.

\section{"[...] a menor taxa de sobrevivên-} cia entre pacientes negros com cân- 
cer de pulmão de pequeno estágio em fase inicial, em comparação com os pacientes brancos ${ }^{(14)}$."

"Um numero significativo de trabalhos mostra que os pacientes negros experimentam maiores probabilidades de morte após trauma em comparação aos pacientes brancos $^{(15) ”}$.

Segundo Rafael, citado por Cameron $^{(12)}$, povos indígenas ainda sofrem uma sobrecarga de doença, tais como o início da doença crônica e incapacidade em idades mais jovens do que suas contrapartes não-indígenas.

$\mathrm{O}$ autor relata ainda que $\mathrm{o}$ acesso a serviços de saúde trata não apenas da habilidade dos indivíduos ou comunidades receberem assistência dos serviços essenciais, mas também como esses serviços são disponibilizados no local de atendimento ${ }^{(12)}$.

De acordo com relatos de Smedley, Stith e Nelson, em 1986, citados por Vernon $^{(16)}$, segundo os dados do Centro de Controle e Prevenção (CDC), de 1986 a 2001, as mulheres representavam somente $7 \%$ dos casos de AIDS em todo o país, já em 2000 eles passam a representar $17 \%$ dos casos. O alerta da doença aumenta diante da população étnica, principalmente entre as mulheres étnicas. O Census Bureau, 2001 - US, relata que nos Estados Unidos, a população étnica é constituída por uma minoria de aproximadamente $24,9 \%$, no entanto eles correspondem a $58 \%$ dos casos de AIDS encontrados de acordo com a CDC 2001. Diferente da crença popular que diz estar diminuindo a crise de AIDS, essa infecção está em crescendo rapidamente principalmente entre as mulheres de cor, onde mulheres étnicas são compostas por $29 \%$ (menos de um terço), de todas as mulheres dos Estados Unidos, no entanto, de acordo com a CDC de 2001, representa $79 \%$ da comunidade do sexo feminino colonizadas pela $\operatorname{AIDS}^{(16)}$.

Desde a chegada dos colonizadores, os povos indígenas sofrem maus tratos,
Desde a chegada dos colonizadores, os povos indígenas sofrem maus tratos, trabalhos forçados, confinamentos e sedentarização. Um número bem sugestivo desse povo acaba por desaparecer devido

ao processo de colonização, onde foi mais evidenciadas as práticas de escravidão, chacinas, guerras, e epidemias por doenças infecciosas. trabalhos forçados, confinamentos e sedentarização. Um número bem sugestivo desse povo acaba por desaparecer devido ao processo de colonização, onde foi mais evidenciadas as práticas de escravidão, chacinas, guerras, e epidemias por doenças infecciosas. Assim sendo, o autor afirma que os povos indígenas sempre sofreram com essa marca de preconceito e descaso em relação ao Estado brasileiro ${ }^{(17)}$.

As medidas que podem trazer uma resolução para as disparidades de saúde devem ser executadas de cima para baixo, de baixo para cima, e a partir do meio em ambas as direções. Seguindo a sugestão da OIM, começando pelas leis e políticas, uma das formas é por meio dos direitos existentes de direitos civis. Além disso, poderiam ser implementadas pelas agências de acreditação para os hospitais, políticas formais que propõem medidas inerentes para suprimir as disparidades que englobam esses grupos vulneráveis. E para que haja redução das disparidades de saúde de forma mais eficaz, existe a necessidade de legislações específicas e regulamentos com exigências do sistema de saúde e organizações de cuidados gerenciados ${ }^{(18)}$.

A Política Nacional de Saúde Integral da População Negra (PNSIPN), bem como a Política Nacional de Atenção à Saúde dos Povos Indígenas (PNASPI), constrói um modelo de gestão que integra todos os grupos étnicos da sociedade ao direito à saúde através da promoção da saúde, na atenção e no cuidado em saúde, dando prioridade à redução das desigualdades étnico-raciais, ao combate ao racismo e à discriminação nas organizações e serviços do Sistema Único de Saúde. Diante do exposto, cabe salientar a importancia de uma assistência adequada a essa população devido ao tempo de discriminação sofrido. A saúde está pautada como direito de todos e essencialmente daquelas pessoas que estão em zonas mais vulneráveis das comunidades. $\mathrm{O}$ autor conclui que é de suma importância o conhecimento das Políticas de Saúde que possui acesso às ações e serviços de saúde para todos ${ }^{(19)}$. 


\section{artigo}

\section{CONCLUSÃO}

Diferentes estudos demonstram que as populações que são consideradas as "minorias", do ponto de vista de acesso e direitos nos serviços de saúde, vem sofrendo situações de racismo, discriminação e preconceito nos diferentes dispositivos de saúde e em seus diferentes graus de complexidade.

Diante desta realidade, é vigente e urgente o fomento de discussões no Brasil que ultrapassem o desvendar das iniquidades existentes no sistema de saúde de maneira efetiva, que venha a colaborar no entendimento de como essas situações acontecem e de que maneira essas disparidades influenciam/atuam na saúde da população negra.

Outro ponto de suma importância para melhorar o rastreamento e (re) conheci- mento dessas iniquidades é descentralizar as pesquisas de maneira que sejam levadas em consideração a dimensão continental de nosso país e a capilaridade territorial que nos proporciona uma grande diversidade étnico-racial, com acréscimo das particularidades regionais.

O racismo institucional presente nos serviços de saúde pode ser classificado como antiético por sua própria nature$\mathrm{za}$, pois envolve valores que provocam controvérsia. Tanto se fala em equidade como a estratégia de tratar os desiguais de maneira desigual, respeitando suas especificidades e não é possível mesurar as consequências das práticas de equidade.

A ética do cuidado compreende que a capacidade de agir eticamente é uma "virtude ativa" que necessita de dois sentimentos: o primeiro é o sentimento natural de cuidado e o segundo quando existe as respostas à lembrança do primeiro, visto que cada indivíduo traz consigo uma recordação dos momentos em que cuidou ou foi cuidado e caso deseje, poderá acessá-la, por ela direcionar sua conduta. Existem momentos nos quais o cuidar se mostra como algo completamente natural, sem que haja imposição a conflitos éticos, visto que tanto o "querer" quanto o "dever" coincidem.

Em suma, a ética no cuidado vem para fundamentar nossas funções e responsabilidades diante dos clientes. Ao refletirmos sobre a forma como estamos realizando os cuidados e as consequências de nossos atos sobre os pacientes, passamos a dar valor a todos os nossos atos, desde os menores atos até as grandes ações.

\section{REFERÊNCIAS}

1. Ministério da Saúde, Secretaria de Gestão Estratégica e Participativa, Secretaria Especial de Políticas de Promoção da Igualdade Racial (BR). Política Nacional de Saúde Integral da População Negra. Brasília (DF): MS; 2010.

2. Nora CRD, Zoboli ELCP, Vieira MM. Deliberação ética em saúde: revisão integrativa da literatura. Revista Bioética. 2015;23(1):114-23.

3. Minayo MCS. O desafio do conhecimento. 10. ed. São Paulo: Hucitec; 2007.

4. Mendes KDS, Silveira RCCP, Galvão CM. Revisão integrativa: método de pesquisa para a incorporação de evidências na saúde e na enfermagem. Texto contexto - enferm. 2008 Oct/Dec;17(4):758-64.

5. Bardin L. Análise de Conteúdo. São Paulo: Edições 70; 2011.

6. Durey A, Thompson SC. Reducing the health disparities of Indigenous Australians: time to change focus. BMC Health Serv Res. 2012 Jun; 12:151.

7. Kalckmann S, Santos CG, Batista LE, Cruz VM. Racismo Institucional: um desafio para a equidade no SUS? Saúde Soc. São Paulo. 2007;16(2):146-155.

8. Kwame $M$, Kamaldeep $B$. Institutional racism in mental health care. BMJ. 2007 Mar;334(7595):649-650.

9. Santos IAAS. Direitos humanos e as práticas de racismo. [recurso eletrônico]. Brasília: Câmara dos deputados, edições Câmara, 2013. 298 p.

10. Leite MP. Preconceito racial e racismo institucional no Brasil: algumas reflexões. Círculo Palmarino. Maio, 2012.

11. Werneck, J. Racismo Institucional Uma Abordagem Con- ceitual. ONU Mulheres; 2013.

12. Cameron BL, Carmargo PMDP, Salas AS, Bourque BRL, Hungler $\mathrm{K}$. Understanding inequalities in access to health care services for aboriginal people: a call for nursing action. ANS Adv Nurs Sci. 2014;37(3):E1-E16.

13. Stephens C. Racism and inequalities in health: notes towards an agenda for critical health psychology. 2009 Jul; 14(5):655-9.

14. Betancourt JR, Corbett J, Bondaryk MR. Addressing disparities and achieving equity: cultural competence, ethics, and health-care transformation. Chest. 2014 Jan;145(1):143148.

15. Haider $\mathrm{AH}$, et al. Unconscious race and social class bias among acute care surgical clinicians and clinical treatment decisions. JAMA Surg. 2015 May;150(5):457-64.

16. Vernon IS. American Indian women, HIV/AIDS, and health disparity. Substance use \& misuse. 2007;42(4):741-752.

17. Altini E, Rodrigues G, Padilha L, Moraes PD, Liebgott RA. (Organizadores). A Política de Atenção à Saúde Indígena no Brasil: Breve recuperação histórica sobre a política de assistência à saúde nas comunidades indígenas. Publicação do Conselho Indigenista Missionário - CIMI. Organismo vinculado à Conferência Nacional dos Bispos do Brasil - CNBB. Edição Revisada (versão para circulação restrita). 2013.

18. Stone J. Race and healthcare disparities: overcoming vulnerability. Theoretical Medicine. 2002;23:499-518.

19. Silva CHF, et al. Relato Sobre As Políticas De Saúde Da População Negra E Indígena No Brasil. Revista da Associação Brasileira de Pesquisadores/as Negros/as (ABPN). 2015 jun;7(16):16-27. 